\title{
The Effects of Amino Acid Supplementations during Weaning on Starter Intake and Growth of Dairy Calves
}

\author{
DOI:10.31274/air.11928 \\ Can Ayhan Kaya, Visiting Professor, \\ Dicle University, Turkey; \\ Janaka Wickramasinghe, Graduate Research Assistant; \\ Ranga Appuhamy, Assistant Professor, Department of \\ Animal Science
}

\section{Summary and Implications}

Supplementation of L-glutamine (Gln) at 1.0\% of DMI has shown to enhance immune function, alleviate stress and promote growth in weaned piglets. Branched-chain amino acids (BCAA) particularly leucine are known to promote muscle growth. Those enhancements are critical for calves undergoing weaning particularly from a high volume of milk at an early age. In the present study we examined the effects of a Gln supplement (1.0\% of DMI) with or without BCAA on starter intake and growth performance of dairy calves weaned early ( $35 \mathrm{~d}$ of age) from a high milk volume $(9.0 \mathrm{~L} / \mathrm{d})$. A separate group of calves not receiving any amino acid supplement served as the control (CTL). All calves were partially weaned restricting the milk volume to $3.0 \mathrm{~L} / \mathrm{d}$ at 35 $\mathrm{d}$ of age. The amino acids were fed mixing in milk during the first week of weaning ( 35 to $42 \mathrm{~d}$ ). While having $9.0 \mathrm{~L}$ of milk, calves consumed zero grain but had average daily gain (ADG) close to $0.9 \mathrm{~kg} / \mathrm{d}$. Even though milk volume restriction significantly increased starter intake, it was associated with a significant growth depression that was not alleviated by Gln or Gln plus BCAA during the first week of weaning. During the second week of weaning, calves had ADG that was comparable to pre-weaning growth rates. Regardless of treatments, calves achieved $1.0 \mathrm{~kg} / \mathrm{d}$ starter intake within $16 \mathrm{~d}$ after partial weaning and thus weaned completely at $51 \mathrm{~d}$ of age. Calves supplemented with Gln or Gln plus BCAA was related to significantly lower starter intake and body weight than CTL post weaning (49 to $70 \mathrm{~d}$ ). In conclusion, supplementation of Gln (1\% of DMI) alone or with BCAA was not successful in mitigating growth depression associated with weaning. On the other hand, they negatively affected starter intake post-weaning suggesting a lasting impact on mechanisms governing feed intake. The present study demonstrated that $1.0 \mathrm{~kg} / \mathrm{d}$ starter intake can be achieved at 7 week of age by employing a step-wise weaning scheme for dairy calves fed a high volume of milk.

\section{Introduction}

Early weaning is an important prospect as raising a preweaned heifer calf is expensive $(\$ 6.50 / \mathrm{calf} / \mathrm{d})$. Even though several research trials have shown a potential to wean calves as early as 4 to 5 weeks of age, dairy producers in the US wait until about 9 weeks to wean dairy calves. Nonetheless, earlyweaning can be a stressful event negatively affecting growth and wellbeing of calves during and after weaning. Therefore, early weaning schemes should assure smooth transition from a liquid to a solid diet, particularly when calves are fed high volumes of milk or milk replacer, which are more common now than in the past. Treating animals to optimize immune function and nutritional status during weaning has been shown to help them handle weaning stress as reflected by improved weight gain that is suppressed otherwise during weaning. In this regard, L-glutamine (Gln), a dispensable amino acid, has shown promising results in pigs undergoing weaning. However, Gln supplementation was associated with low plasma concentrations of indispensable amino acids; leucine, isoleucine, and valine collectively called branchedchain amino acid (BCAA) in early-weaned calves and piglets suggesting those amino acids were limiting. Also considering the ability of BCAA to stimulate muscle growth, it can be hypothesized that co-supplementation of BCAA and Gln would help alleviate weaning stress and thus improve average daily gain (ADG) and starter intake during weaning. The objective of this study was to examine the effects of glutamine supplementation with or without a BCAA supplementation on starter intake and growth performance of early-weaned calves during and few weeks after weaning.

\section{Materials and Methods}

All animal procedures were approved by Animal Care and Use Committee at Iowa State University. The study was conducted from May to August of 2019 at Iowa State University dairy farm. Thirty three Holstein heifer calves were enrolled in the study at $28 \mathrm{~d}$ of age, weaned partially at $35 \mathrm{~d}$ of age by decreasing milk allowance (pasteurized waste milk) 9 to $3 \mathrm{~L} / \mathrm{d}$, and assigned to one of three amino acid supplements $(\mathrm{n}=11)$ during the first week of weaning.

1) CTL: no AA supplementation

2) Gln: a supplementation of Gln ( $7 \mathrm{~g}$ or $1.0 \%$ of $\mathrm{DMI} / \mathrm{d})$

3) GIn+BCAA: a supplementation of $\operatorname{Gln}(7 \mathrm{~g} / \mathrm{d})$, Lleucine $(17 \mathrm{~g} / \mathrm{d})$, L-Isoleucine $(10 \mathrm{~g} / \mathrm{d})$, and L-Valine $(11 \mathrm{~g} / \mathrm{d})$

In previous studies, Gln supplementations at $1.0 \%$ of $\mathrm{DMI} / \mathrm{d}$ has shown favorable effects in weaned piglets but

Copyright (C) 2020 by the Authors. This is an open access article published under the CC BY-NC license (https://creativecommons.org/licenses/by-nc/4.0/), which allows for non-commercial reuse with proper attribution. 
decreased starter intake of pre-weaned dairy calves. We chose the same dose to examine how it would work alone or together with BCAA in calves undergoing weaning. The BCAA doses were determined to be comparable with estimated BCAA losses resulting from milk volume restriction. Calves in all three groups were weaned completely once they reach $1.0 \mathrm{~kg}$ of starter intake over two consecutive days. Daily starter intake of individual calves was recorded throughout the study ( 28 to $70 \mathrm{~d}$ of age). Body weight (BW), heart girth, hip height, hip width, and body length were recorded weekly during that period. Statistical significance of the treatment effects on starter intake, and growth measurements were analyzed using a model including fixed effects of treatments, period (pre-, during, and postweaning), and treatment $\times$ period interaction, and random effect of calf with MIXED Procedure of SAS (9.4 version). The least squares means were compared using Tukey Kramer test. The interactions of treatments with slope at which body weight or starter intake changed post-weaning were analyzed using REG procedure of SAS.

\section{Results and Discussion}

Starter intake, BW and other body measurements were similar among calves pre-weaning (Figure 1A and Table 1). Regardless of treatments, calves consumed a negligible amount of starter $(0.08 \pm 0.08 \mathrm{~kg} / \mathrm{d})$, while having $9.0 \mathrm{~L} / \mathrm{d}$ milk pre-weaning $(28$ to $35 \mathrm{~d})$. Starter intake increased significantly $(0.42 \pm 0.09 \mathrm{~kg} / \mathrm{d})$, once calves weaned by restricting the milk allowance to $3.0 \mathrm{~L} / \mathrm{d}$. Amino acid supplements did not affect how fast calves increased starter intake during weaning. Calves took nearly $16 \mathrm{~d}$ to achieve 1.0 $\mathrm{kg} / \mathrm{d}$ starter intake and thus weaned completely at $51 \mathrm{~d}$ of age irrespective to treatments. Partial weaning significantly decreased ADG during the first week of weaning. Amino acid supplements did not have a significant control over it. All calves gained significant weight during rest of the weaning but ADG of Gln+BCAA tended to be lower than that of CTL $(P=0.091)$. Once weaned completely, starter intake increased sharply, irrespective of treatments $(P<0.001)$. The increment of starter intake in Gln+BCAA was slower $(P<$ $0.001)$ than that of CTL and Gln post-weaning (Figure 1A). Concomitant BW changes also exhibited similar pattern (Figure 1B). The average starter intake and BW of Gln and Gln+BCAA were lower than CTL post-weaning $(P<0.050$, Table 1).

\section{Conclusions}

As opposed to our hypothesis, the supplementations of Gln and BCAA were not successful in alleviating growth depression associated with weaning. On the other hand, the amino acids negatively affected starter intake post-weaning suggesting a lasting impact of dietary amino acid imbalances on regulation of feed intake in calves. Potential alterations in gut microbiota composition by amino acid supplements could also contribute to those effects. The present study demonstrated that $1.0 \mathrm{~kg} / \mathrm{d}$ starter intake can be achieved at 7 wk of age by employing a step-wise weaning scheme for dairy calves fed a high volume of milk.

\section{Acknowledgements}

We appreciate the support received from the staff at Iowa State University. Ajinomoto Animal Nutrition North America Inc (Chicago, IL) is acknowledged for their donations of L-glutamine, L-leucine, L-isoleucine, and Lvaline.


Figure 1. Mean starter intake (A) and body weight (B) of calves receiving no amino acid supplement (CTL), Lglutamine (Gln), or L-Glutamine plus BCAA (Gln+BCAA) during the first week of weaning. Weaning was begun decreasing daily milk allowance from 9 to $6 \mathrm{~L}$ at $35 \mathrm{~d}$ of age. Calves were weaned completely as they achieved $1.0 \mathrm{~kg} / \mathrm{d}$ starter intake at about $41 \mathrm{~d}$ of age. 
Table 1. Starter and drinking water intake, and growth performance of calves supplemented with no amino acid supplement (CTL), only L-glutamine (Gln), or L-glutamine plus leucine, isoleucine and valine (Gln + BCAA) during the first week of weaning ( 35 to $42 \mathrm{~d}$ of age).

\begin{tabular}{|c|c|c|c|c|c|}
\hline \multirow[b]{2}{*}{ Variable } & \multicolumn{3}{|c|}{ Least squares means } & \multirow[b]{2}{*}{ SEM } & \multirow[b]{2}{*}{$P$ - value } \\
\hline & CTL & Gln & Gln+BCAA & & \\
\hline \multicolumn{6}{|l|}{ Pre-weaning } \\
\hline Starter DM intake, $\mathrm{kg} / \mathrm{d}$ & 0.086 & 0.071 & 0.093 & 0.081 & 0.984 \\
\hline Drinking water intake, $\mathrm{kg} / \mathrm{d}$ & 2.586 & 1.987 & 2.373 & 0.415 & 0.592 \\
\hline Body weight, kg & 63.01 & 63.16 & 64.1 & 1.48 & 0.856 \\
\hline Hip height, cm & 86.51 & 86.48 & 87.38 & 0.56 & 0.430 \\
\hline Hip width, $\mathrm{cm}$ & 22.32 & 22.04 & 22.56 & 0.25 & 0.344 \\
\hline Body length, $\mathrm{cm}$ & 80.21 & 79.64 & 80.82 & 0.99 & 0.708 \\
\hline $\mathrm{ADG}, \mathrm{kg} / \mathrm{d}$ & 0.85 & 0.82 & 0.88 & 0.11 & 0.912 \\
\hline \multicolumn{6}{|l|}{ During weaning } \\
\hline Days to reach $1.0 \mathrm{~kg}$ of starter intake & 15.8 & 16.8 & 14.0 & 1.47 & 0.226 \\
\hline Age completely weaned, $\mathrm{d}$ & 50.6 & 51.6 & 48.9 & 1.47 & 0.226 \\
\hline Starter intake (first week), $\mathrm{kg} / \mathrm{d}$ & 0.39 & 0.37 & 0.49 & 0.087 & 0.557 \\
\hline Starter intake (rest of the weaning), $\mathrm{kg} / \mathrm{d}$ & 0.89 & 0.72 & 0.77 & 0.091 & 0.376 \\
\hline Drinking water intake, $\mathrm{kg} / \mathrm{d}$ & 4.545 & 4.389 & 4.549 & 0.387 & 0.952 \\
\hline Body weight, kg & 68.96 & 68.34 & 69.8 & 1.51 & 0.793 \\
\hline Hip height, cm & 89.51 & 90 & 89.34 & 0.57 & 0.701 \\
\hline Hip width, $\mathrm{cm}$ & 22.94 & 23.17 & 23.51 & 0.25 & 0.306 \\
\hline Body length, $\mathrm{cm}$ & 82.77 & 84.25 & 84.98 & 1.00 & 0.298 \\
\hline ADG (first week), kg/d & 0.18 & 0.08 & 0.32 & 0.1 & 0.247 \\
\hline $\mathrm{ADG}$ (rest of the weaning), $\mathrm{kg} / \mathrm{d}$ & 0.86 & 0.59 & 0.54 & 0.11 & 0.091 \\
\hline \multicolumn{6}{|l|}{ Post-weaning } \\
\hline Starter intake, $\mathrm{kg} / \mathrm{d}$ & $2.756^{\mathrm{a}}$ & $2.441^{\mathrm{b}}$ & $2.24^{\mathrm{b}}$ & 0.082 & 0.001 \\
\hline Drinking water intake, $\mathrm{kg} / \mathrm{d}$ & $10.063^{\mathrm{a}}$ & $9.750^{\mathrm{a}}$ & $8.580^{\mathrm{b}}$ & 0.368 & 0.015 \\
\hline Body weight, $\mathrm{kg}$ & $89.48^{\mathrm{a}}$ & $85.41^{\mathrm{b}}$ & $85.58^{b}$ & 1.06 & 0.012 \\
\hline Hip height, cm & 93.82 & 94.06 & 93.60 & 0.40 & 0.723 \\
\hline Hip width, cm & 24.45 & 24.28 & 24.52 & 0.18 & 0.628 \\
\hline Body length, $\mathrm{cm}$ & 89.16 & 88.93 & 89.20 & 0.71 & 0.960 \\
\hline $\mathrm{ADG}, \mathrm{kg} / \mathrm{d}$ & 0.99 & 0.95 & 1.00 & 0.07 & 0.886 \\
\hline ADG: Starter intake & 0.42 & 0.45 & 0.52 & 0.06 & 0.522 \\
\hline
\end{tabular}

*calves were weaned completely when they reached $1.0 \mathrm{~kg} / \mathrm{d}$ starter intake over two consecutive days 